\title{
The Migration Challenge for PAYG
}

\author{
Gurgen Aslanyan* \\ CERGE-EI’ Prague
}

October 2013

\begin{abstract}
Immigration has been popularised in the economics literature as a tool that could be used to balance troubled PAYG pension systems. Pivotal research by Razin and Sadka shows that unskilled immigration can overcome the pension problem and, further, boost the general welfare in the host economy. However, a large strand of current economics research is engaged in identifying mechanisms through which unskilled immigration, while solving the pension problem, is causing undesired shifts in general welfare. This work shows that recurring unskilled immigration will not only reduce the general welfare, but may be challenging the very pension system by reducing the pension benefits themselves. Further, interpreting the actual data, it is suggested that immigration policies are designed either based on public finances only or in a political environment of gerontocracy .

Keywords: Public Pensions, PAYG, Unskilled Migration, Capital Dilution

JEL Classification: J18, F22, H55
\end{abstract}

${ }^{*}$ Tel. (+420) 77660 6804, E-mail: Gurgen.Aslanyan@cerge-ei.cz

${ }^{\dagger}$ CERGE-EI, a joint workplace of Charles University and the Economics Institute of the Academy of Sciences of the Czech Republic, Politickych veznu 7, 11121 Prague, Czech Republic. 


\section{Introduction}

Decreased fertility, along with increased longevity, challenges the sustainability of unfunded pay-as-you-go (PAYG) pension systems in most developed economies: Decreased fertility shrinks the contribution base, while increased longevity burdens the system with more pension claims. Thus, sustainability of the system requires urgent reforms: parametric, demographic, or a combination of the two. Parametric reforms include increased pension contributions, decreased benefits, or a combination of the two. Those parametric reforms, however, are welfare impairing: increased contributions harm the working-age population, while the old-age suffer from decreased benefits.

Demographic reforms are the theoretical alternative to the parametric reforms. Two main lines of literature exist on the demographic alternatives. The first line discusses the problems within native-born populations, i.e. fertility enhancing policies (Cigno, 2010) and human capital accumulation (Cremer, Gahvari, and Pestieau, 2011), while the second discusses the possibility of substituting nativeborn population with immigrants (Razin and Sadka, 1999; Schou, 2006). Much of the literature focuses on studying the welfare effects of those immigration reforms. The current paper, however, shows that immigration reforms are mostly 'equivalent' to parametric reforms in the sense that they decrease the pension benefits (and thus are not meaningful alternatives). The focus of the current paper is on unskilled immigration to an economy with an unfunded defined-contribution PAYG pension system.

Already, Razin and Sadka (1999) show that unskilled immigration can overcome the PAYG challenge: Unskilled immigrants do not merely pay the required contribution but, potentially, increase the welfare to everyone. Thus, immigrants come in and pay the necessary contributions required for the system's sustainabil- 
ity. When they age, they increase the number of claims on benefits; however, their children would then contribute to the pension system (and bring back the initial equilibrium).

Since Razin and Sadka (1999) much has been written to show various channels through which increases in unskilled immigration could decrease the general welfare (hence implying that demographic reforms are not preferred to parametric reforms). Thus, Razin and Sadka (2000) claim that the pension benefits are increased with increased unskilled immigration, but, in the case of closed economies, the wages would decline and thus hurt those who mostly rely on labour for income.

Casarico and Devillanova (2003) noted that a wage decline caused by an influx of unskilled immigrants would change the skill distribution among the natives in the host economy. They show the changes that come with the possibility of endogenous skill upgrades can cause many inter- and intra-generational welfare re-distribution conflicts. Jinno (2011) develops the idea further incorporating the possibility of an endogenous skill upgrade for the immigrants as well while noting that there are some assimilation costs. The results suggest further re-distributional conflicts. Krieger (2004) claims that welfare impairment and re-distribution already occur when high immigrant fertility rates and the low skill levels of immigrant children are accounted for.

Kemnitz $(2003,2008)$ introduces the problem of unemployment into the analysis. He claims that unskilled immigration increases unemployment and harms the unskilled natives even though there is a boon to general welfare. Muysken, Cörves and Ziesemer (2011) in a similar manner show that unskilled immigration increases unemployment, and if their skills are not upgraded, unskilled immigrants may impair the general welfare.

Many large-scale computational studies have been conducted in order to analyse 
whether immigration can make the PAYG pension systems sustainable. Thus, Lee and Miller (2000) and Storesletten (2000) model the US economy and conclude that some immigration can help alleviate the aging problem of the baby-boom generation. Schou (2006) presents a similar detailed study for Denmark and concludes that immigrants are net beneficiaries of the public pension system while their contribution to economic growth is marginal. More recently, Chojnicki, Docquier, and Ragot (2012) presented a retrospective study on the US economy and concluded that a higher level of immigration would have been beneficial to the general welfare of the population. However, their study was concentrated on the short- to medium-term effects of immigration and did not study possible long-term effects.

Meanwhile, there is a strand of literature claiming that only an excessively large inflow of immigrants can help sustain the pension system. For instance, Übelmesser (2004) claims that the EU cannot accommodate as many migrants as is needed for pension system sustainability and claims that parametric reforms are also necessary. Blake and Mayhew (2006) study a combination of parametric reforms with immigration, claiming that the need for immigrants into the UK will be constantly growing if the pension system is not reformed. Serrano, Eguía and Ferreiro (2011) claim that even with recent, large immigration, it is not possible to sustain the current Spanish pension system, and parametric reforms are inevitable.

The current paper, claiming that under certain conditions unskilled immigration may result in lower pension benefits (with pension contributions being fixed), shows that increased immigration is not desirable. The paper utilises the idea of a multi-period immigration policy, i.e. immigrants enter the economy each period as opposed to the one-time-migrant-inflow framework of Razin and Sadka (2000). While in the Razin and Sadka model the old equilibrium is restored after a number 
of periods, multi-period immigration results in a new equilibrium, distinct from the initial one. This allows studying the reaction of the economy in full, i.e. both in the new equilibrium and on the transition path. An important channel that links unskilled immigration to pensions is studied: The paper employs the framework of several recent publications by Fanti and Gori $(2010,2012)$ that follows the dynamics of per-capita capital in a Diamond-type overlapping-generations model. Thus, the paper connects unskilled immigration to distortions in savings and demographics that result in lower capital per capita and thus in generally lower wages. Hence, even though pension benefits grow compared to wages (as in Razin and Sadka, 1999), wages may decrease such that benefits are less than what they would be without the immigrants.

The current paper also complements the literature that studies the negative spiral of the PAYG system and demography (e.g. Cigno, 2006; Cipriani, 2013), as it shows how designed immigration policy intended for supporting the system actually burdens it further.

In line with the literature, general welfare changes are also discussed: Such a study in the heterogeneous agent framework allows analysing the political feasibility of immigration policy reform. Similar to Razin, Sadka and Suwankiri (2011) and Lacomba and Lagos (2010), the current paper identifies those policies that the current population might favour. Furthermore, in contrast to Lacomba and Lagos, this paper allows the population to chose immigrant skill level and follows the long-term welfare effects of the adopted policies. Numerical examples are used to support the results of the theoretical framework.

The rest of the paper is organised as follows: Section 2 introduces the economic environment. Section 3 defines the equilibrium and provides the pension system analysis under migration. Section 4 analyses the political equilibrium and 
transitional dynamics, and the concluding remarks are in the final section.

\section{The Economic Environment}

Two overlapping generations exist in a closed economy. During the first period of their lives the agents work (for remuneration), save and consume. For the second period the agents consume their pension benefits and savings. The firm organises production by hiring labour and capital from households. The government collects the pension contributions from the working-age young and distributes them within retired (old-age) population. All markets clear.

\subsection{Population}

Each period young migrants are allowed into the country equal to $\mu$ share of the native young. Thus, the total working-age population in the economy is:

$$
T_{t}=N_{t}(1+\mu)
$$

where $N_{t}$ is the size of the native-born population with the following dynamics.

$$
N_{t}=N_{t-1}(1+\mu) n,
$$

where it is assumed that immigrants and their descendants have the same fertility rate $(n-1)$. However, the immigrants have only $\varepsilon$ of the skill level of the native population. Thus, the efficient labour in the country at any time is:

$$
L_{t}=N_{t}(1+\mu \varepsilon)
$$

and is different from the total size of the population. 


\subsection{Households}

Each household is represented by a single agent that solves a lifetime utility maximisation problem:

$$
\mathbb{U}_{t}=\max \left(\ln c_{i, t}+\beta \ln c_{i, t+1}\right)
$$

subject to the budget constraints:

$$
\begin{aligned}
c_{i, t}+s_{i, t} & =w_{t} e_{i}(1-\tau), \\
c_{i, t+1} & =p_{t+1}^{d}+p_{i, t+1}^{e r}+s_{i, t}\left(1+r_{t+1}\right),
\end{aligned}
$$

where $i$ shows the status in the country (native born or migrant), $c_{i, t}$ and $s_{i, t}$ are, respectively, the consumption and savings of type $i$ agent at time $t, e_{i}$ shows the efficiency of the worker (which is unity for native born and $\varepsilon$ for immigrants), $\tau$ is the tax rate that has two components $\tau=\tau^{d}-\tau^{e r}$, where $\tau^{d}$ and $\tau^{e r}$ are, respectively, the pension contribution rates to the demogrant and earnings-related pension systems, $p_{t}^{d}$ is the demogrant benefit received equally by all of the retired, while $p_{i, t}^{e r}$ is the earning-related pension benefits that each retired agent receives according to own contribution:

$$
p_{i, t}^{e r}=\varphi_{t} \cdot w_{t} e_{i}
$$

where $\varphi_{t}$ is the pension replacement rate.

Optimal household savings take the value

$$
s_{i, t}=\frac{\beta}{1+\beta} w_{t} e_{i}\left(1-\tau^{d}-\tau^{e r}\right)-\frac{p_{t+1}^{d, e}+\varphi_{t+1}^{e} w_{t+1}^{e} e_{i}}{(1+\beta)\left(1+r_{t+1}^{e}\right)},
$$

where $p_{t+1}^{d, e}, \varphi_{t+1}^{e}, w_{t+1}^{e}$ and $r_{t+1}^{e}$ are the expected values of the pension benefits, replacement rate, wage, and interest rate respectively. 


\section{$2.3 \quad$ Firms}

There is one firm that uses the Cobb-Douglas production function ${ }^{1}$ with an $\alpha$ share of capital. Hence, the usual optimality conditions hold:

$$
\begin{aligned}
& w_{t}=(1-\alpha) A k_{t}^{\alpha}, \\
& r_{t}=\alpha A k_{t}^{\alpha-1}-1,
\end{aligned}
$$

where $k_{t}$ is the capital per effective labour.

\subsection{The Pension System}

Two parallel pension systems will be accounted for: a demogrant (Beveridgean tradition) system that evenly distributes the income over the retired population and the earnings-related pension system (Bismarckian tradition) that is actuarially fair. Pension systems run periodically balanced budgets, i.e. the contributions collected are given out as benefits. Thus, the earnings-related pension system can be presented as

$$
p_{t}^{e r} L_{t-1}=\tau^{e r} w_{t} L_{t}
$$

Using (2) and (3), the earnings-related benefit size can be calculated as

$$
p_{i, t}^{e r}=\tau^{e r} w_{t} e_{i}(1+\mu) n
$$

where $p_{i, t}^{e r}=p_{t}^{e r} e_{i}$ is the (efficiency-weighted) pension that type $i$ agent gets at period $t$. Similarly, the demogrant system can be represented as

$$
p_{t}^{d} T_{t-1}=\tau^{d} w_{t} L_{t}
$$

\footnotetext{
${ }^{1}$ Certainly, the assumed perfect substitutability of skilled and unskilled workers brings obvious limitations to the model. However, there are two main reasons for this assumption: First, the current assumption makes the comparison of the results with the main body of the literature straightforward (as the assumption is the most common); and second, the empirical literature on the topic has not identified the exact relationship yet (e.g. Okkerse, 2008).
} 
Using (1) and (3), the pension benefits can be calculated as

$$
p_{t}^{d}=\tau^{d} w_{t}(1+\mu \varepsilon) n
$$

i.e., as in Razin \& Sadka (1999) the first-order effect of the immigrants on pensions is strictly positive.

\section{Equilibrium}

Given the parameter values, $\alpha, \beta, \varepsilon, \mu, \tau^{d}, \tau^{e r}$, and the initial values $K_{o}, N_{o}$, the equilibrium is an allocation $\left\{c_{i, t}, s_{i, t}, p_{t}\right\}$ and a price vector $\left(w_{t}, r_{t}\right)$ such that the population follows the dynamics given by (1) and (3), households optimise their problem (4)-(7), the firm optimises so that (9) and (10) hold, pension budgets (11) and (13) are balanced, and the capital market clears, i.e.

$$
K_{t+1}=N_{t} s_{n, t}+N_{t} \mu s_{m, t}
$$

It is assumed that the economy starts in a steady state with no migration. Once immigration is allowed, the economy undergoes a transition and eventually reaches a new, post-migration steady state.

\section{$3.1 \quad$ Post-Migration Capital}

Aggregate capital in the economy can be calculated based on (15), using the population dynamics (2) and the optimal savings (8). Thus,

$$
K_{t+1}=\left[\frac{1+\mu \varepsilon}{1+\beta}\left(w_{t}(1-\tau) \beta-\frac{\varphi_{t+1}^{e} w_{t+1}^{e}}{1+r_{t+1}^{e}}\right)-\frac{1+\mu}{1+\beta} \frac{p_{t+1}^{d, e}}{1+r_{t+1}^{e}}\right] \frac{N_{t+1}}{n(1+\mu)}
$$


Using (3), (9), (10), and (14) and assuming that agents have rational expectations, the dynamics of capital per effective labour can be obtained:

$$
k_{t+1}=\frac{\alpha A(1-\alpha)(1-\tau) \beta}{n(1+\mu)(\alpha(1+\beta)+(1-\alpha) \tau)} k_{t}^{\alpha}
$$

that solves for the steady state equilibrium value:

$$
\bar{k}=\left[\frac{\alpha A(1-\alpha)\left(1-\tau^{d}-\tau^{e r}\right) \beta}{n(1+\mu)(\alpha(1+\beta)+(1-\alpha) \tau)}\right]^{\frac{1}{1-\alpha}}
$$

As it can be immediately observed, the capital per effective labour decreases with the size of the immigrant population. However, the post-migration steady state level of capital (18) does not depend on the skill level of the immigrants: Though the immigrants have lower skill level, and thus earn and save less than the natives, in the steady state they are matched to the next period immigrant population that is equal in size and skill level, and thus they do not change the level of the capital per effective labour. Meanwhile, those immigrants father children that are not matched by any savings and thus lower the level of capital available to each effective labour unit. Hence, the capital dilution observed in the postimmigration steady state is caused not by the immigrants per se, but rather by the children of those immigrants.

\section{$3.2 \quad$ Post-Migration Pension Benefits}

As in the previous section, two pension systems will be discussed separately: The equilibrium value of the demogrant pension benefits can be obtained by substituting the steady state wage rate into (14):

$$
\bar{p}^{d}(\mu)=\tau^{e r} B \cdot \frac{1+\mu \varepsilon}{(1+\mu)^{\frac{\alpha}{1-\alpha}}},
$$


where

$$
B=(1-\alpha)\left(A n^{1-2 \alpha}\right)^{\frac{1}{1-\alpha}}\left(\frac{\alpha \beta(1-\alpha)(1-\tau)}{\alpha(1+\beta)+\tau(1-\alpha)}\right)^{\frac{\alpha}{1-\alpha}}
$$

does not change with the size or skill level of the immigrant population. Thus, to understand the effect of immigration on the demogrant pension benefits, it is sufficient to find the sign of the derivative of (19):

$$
\frac{d}{d \mu} p^{*}(\mu)=\frac{\tau^{e r} B}{(1-\alpha)(1+\mu)^{\frac{1-2 \alpha}{1-\alpha}}}(\varepsilon(1+\mu)(1-\alpha)-\alpha(1+\mu \varepsilon)) .
$$

Proposition 1 Demogrant pension benefits decrease with the size of the immigrant population if the skill level of immigrants (compared to natives) is

$$
\varepsilon<\frac{\alpha}{1-\alpha+\mu(1-2 \alpha)}
$$

while $\alpha<\frac{1+\mu}{1+2 \mu}$.

Proof. The pension benefits decrease if the derivate (20) is negative. Since the first part (the ratio) of the product on the right-hand side of (20) is a positive constant, the sign of the derivative depends on the sign of the second part and is negative given that the conditions above would be satisfied.

The proposition effectively claims that even though post-migration pensions are higher compared to wages, the immigration-caused capital dilution may be stronger and result in wages that generate lower pension benefits compared to their pre-migration levels. In more detail, the logic is as follows: In post-migration steady state the efficient population dynamics is stabilised on the level of immigration size $(1+\mu)$, which (given the diminishing marginal returns) results in a capital dilution with the size of $(1+\mu)^{\frac{1}{1-\alpha}}$ and a wage decrease with a magnitude of $(1+\mu)^{\frac{\alpha}{1-\alpha}}$. Meanwhile, with population dynamics stabilised, each period there are more contributions from the immigrants that increased the efficient size of the population by $(1+\varepsilon \mu)$. Hence, when the improved demographics of the pension 
system does not cover the decreased effective wage, pensions decrease. For example, if $\alpha=0.4$ and the immigration is under five per cent $(\mu<0.05)$, then immigrants with even sixty-five per cent of local efficiency already will force the pension benefits to decrease, as the immigrants' extra contribution to the pension system will not be enough to cover the wage loss caused by capital dilution.

In the case of earnings-related pensions, the behaviour of the post-migration steady state value of the benefits:

$$
\bar{p}^{e r}(\mu)=\tau^{e r} B \cdot(1+\mu)^{\frac{1-2 \alpha}{1-\alpha}}
$$

are obtained by substituting the equilibrium wage rate into (12), and can be studied similarly:

Proposition 2 Earnings-related pension benefits increase with the size of the immigrant population when $\alpha<1 / 2$, and decrease otherwise.

Proof. Directly follows from (22).

Hence, in the case of an earnings-related pension system, as opposed to a demogrant pension system, the pension benefits always grow (in the economically meaningful case of $\alpha<1 / 2$ ). This result is due to the fact that an actuarially fair distribution of earnings-related pensions guarantees that relative benefits increase more (a multiple of $(1+\mu)$ ) than the effective wage decrease (a multiple of $\left.(1+\mu)^{\frac{\alpha}{1-\alpha}}\right)$. That is, the improvements in demographics are stronger than the capital losses.

The corollary of the two prepositions is that the effect of immigration on the steady state level of total pension benefits $\left(\bar{p}^{d}+\bar{p}^{e r}\right)$ depends on the size and efficiency level of the immigrant population as well as on the Bismarckian factor 
$(\mathrm{BF})^{2}$. Thus, if the BF is small and immigration control is poor then the first proposition results will prevail and the pension benefits will decline. The situation is likely to happen in many European countries such as Denmark or the UK that have a low BF — 0 and 0.09 respectively (Krieger \& Traub, 2013) — and are bound by the EU free labour movement policy ${ }^{3}$. The reverse situation (i.e. the results of the proposition 2 prevail) can be expected from countries with a low BF and tight immigration control (such as Australia with a BF 0.03) or a combination of liberal immigration with a high Bismarckian factor (such as Germany and France with BF 0.55 and 0.72 , respectively). In countries where there is moderate immigration control and a moderate BF (such as the USA with BF 0.46), results and the effects on pension benefits will be ambiguous.

\subsection{Post-Migration General Welfare}

Aside from the effects of immigration on pension benefits, immigration also affects the other components of the general welfare - wages and return to capital. The lifetime utility of agents (4) can be rewritten as

$$
\mathbb{U}_{t}=D+(1+\beta) \ln \left(w_{t}\left(1+r_{t+1}\right)(1-\tau)+p_{t+1}^{d}+p_{t+1}^{e r}\right)-\ln \left(1+r_{t+1}\right),
$$

where $D=\ln \frac{\beta^{\beta}}{(1+\beta)^{(1+\beta)}}$. Capital dilution caused by immigration (18) will result in lower wages (9) and higher return to capital (10) that, combined with the conflicting results of the propositions 1 and 2, make the total effect of the immigration on general welfare ambiguous.

For the sake of analytical tractability an environment without pensions is studied, i.e. $\tau^{d}=\tau^{d}=0$. This allows to analyse the effects of immigration on

\footnotetext{
${ }^{2}$ Bismarckian factor (Cremer \& Pestieau, 1998) is a measure of the actuarial fairness of pension systems. It takes values between 0 and 1 , with 0 characterising a purely redistributive (demogrant, Beveridgean) pension system and 1 - a strictly actuarially fair (earnings related, Bismarckian) pension system. In the present stylised model the Bismarckian factor can be presented as $\tau^{e r} /\left(\tau^{e r}+\tau^{d}\right)$.

${ }^{3}$ This result could be used to explain the extra mobility restrictions that the UK employs for the migrants from the new EU member states - Bulgaria, Croatia, and Romania.
} 
non-pension-related welfare and on pensions separately. This separation, however, is based on an assumption that the existence of the pension systems does not significantly distort the savings decision (or alternatively that pension systems are not large). Hence, the results should be treated as an approximation to the general welfare.

Proposition 3 The non-pension welfare decreases with the size of the immigrant population when $\alpha>\frac{\beta}{1+2 \beta}$.

Proof. The utility function (23) in an environment without pensions, i.e. $\tau^{d}=$ $\tau^{d}=0$, will have as a variable part only $(\alpha-(1-2 \alpha) \beta) \ln k$ that changes in the same direction as $k$ when $\alpha>\frac{\beta}{1+2 \beta}$. And from (18) $\bar{k}$ decreases with increase in the size of the immigrant population $\mu$.

As the requirement $\alpha>\frac{\beta}{1+2 \beta}$ is satisfied in any economically meaningful situation, the proposition 3 allows to conjecture that in the post-migration steady state the general welfare decreases with increased immigration assuming that the possible gains from pensions are not excessively large (the numerical examples of the next section support this conjecture). Still, in the extreme, when actuarially fair pension systems are large the general welfare may increase with immigration.

\subsection{Political Equilibrium}

There are numerous ways how immigration policies might be initiated. Here two alternatives are studied: immigration policy set by a social planner and policy based on public choice (voting).

Following Song, Storesletten and Zilibotti (2012), a social planner is maximising general welfare using some weights for each group. Usually, the farther away the group is in time the less weight they get. Still, if the social planner does not discount the future heavily and bases the decision on the effect of immigration 
on the public finances (pensions in this case), the equilibrium solution will be in line with the corollary to propositions 1 and 2, i.e. small-sized and highly skilled immigration will be supported in an economy with a low BF, and larger-sized immigration in the case of a high BF. However, if the social planner bases the decision on the general welfare, the equilibrium will be in line with the above conjecture, i.e. very limited highly skilled immigration will be allowed.

Conversely, following Lacomba and Lagos (2010) and Razin et al. (2011), a public choice approach can be adopted. That is, it is assumed that agents populating the economy in the initial period vote for the policy based on the economic self-interest, i.e. they vote for the policy that guarantees higher general welfare. Further, it is assumed that the policy will be intact once it is voted for. This approach requires studying the welfare of the initial young and retired population. Thus, using (17), the capital dilution caused by immigration in the initial two periods can be presented as

$$
\begin{aligned}
& k_{1}=\frac{\hat{k}}{1+\mu \varepsilon}, \\
& k_{2}=\frac{\hat{k}}{(1+\mu \varepsilon)^{\alpha}(1+\mu)}
\end{aligned}
$$

so, wages and interest rates will accordingly be

$$
\begin{aligned}
w_{1} & =\frac{\hat{w}}{(1+\mu \varepsilon)^{\alpha}} \\
w_{2} & =\frac{\hat{w}}{\left((1+\mu \varepsilon)^{\alpha}(1+\mu)\right)^{\alpha}}
\end{aligned}
$$

and

$$
\begin{aligned}
1+r_{1} & =\frac{1+\hat{r}}{(1+\mu \varepsilon)^{1-\alpha}} \\
1+r_{2} & =\frac{1+\hat{r}}{\left((1+\mu \varepsilon)^{\alpha}(1+\mu)\right)^{1-\alpha}}
\end{aligned}
$$


where $\hat{k}, \hat{w}$, and $\hat{r}$ are the pre-migration steady state levels of the capital per effective labour, wage, and return to capital, respectively.

The initial retired population face their savings from the previous period combined with higher returns caused by capital dilution. Furthermore,

Proposition 4 Both demogrant and earnings-related pension benefits increase with the size of the immigrant population in the first post-migration period.

Proof. From (12), (14) and (26) follows

$$
\begin{gathered}
\hat{p}^{d}=\tau^{d} n \hat{w} \quad<\tau^{d} n \hat{w} \frac{1+\mu \varepsilon}{(1+\mu \varepsilon)^{\alpha}}=p_{1}^{d} \\
\hat{p}^{e r}=\tau^{e r} n \hat{w} \quad<\tau^{e r} n \hat{w} \frac{1+\mu}{(1+\mu \varepsilon)^{\alpha}}=p_{1}^{e r}
\end{gathered}
$$

Though in the first post-migration period the efficient wages are less compared to their previous steady state levels, pension benefits, both demogrant and earnings-related, still increase based on improved demographics. Thus, the initial retired population only gain from any immigration and, further, the higher the skill level of the immigrant population the more they gain.

In the post-migration environment the initial young population face lower wages, higher return to savings, and ambiguous pension benefits. For the sake of analytical tractability the lifetime utility (23) will again be studied in two disjoint cases: pension benefits and utility without pensions. Thus,

$$
\begin{aligned}
U_{1} & =\text { constant }+\ln w_{1}^{1+\beta} \cdot r_{2}^{\beta} \\
& =\text { constant }+\ln \left(\frac{1}{1+\mu \varepsilon} \bar{w}\right)^{1+\beta}\left(\left(\frac{1}{1+\mu \varepsilon}\right)^{\alpha} \frac{1}{1+\mu} \bar{r}\right)^{(1-\alpha) \beta} \\
& =\text { constant }+\ln \bar{w}^{1+\beta} \bar{r}^{(1-\alpha) \beta}+\ln (1+\mu)^{(1-\alpha) \beta}\left(\frac{1}{1+\mu \varepsilon}\right)^{\alpha-(1-2 \alpha) \beta}
\end{aligned}
$$


The only non-constant part of the utility function is the last term on the right-hand side of (32) and it increases with the size of immigration and decreases with the efficiency level, making the initial young population favour low-skilled immigration. The logical interpretation of the result is as follows: Starting from the second period the native-born immigrant children cause capital dilution that results in higher return to capital (savings), and, as the size of the native-born immigrant children is equal to the size of immigrant population, the initial young population prefers large immigration. However, the initial young face those immigrants on the labour market and compete with them for the efficient wage. Thus, the initial young population prefer large-scale low-skilled immigrant population.

As in the case of initial retired population the pre- and post-migration pension benefits for the initial young (second period retired) population can be calculated.

Proposition 5 In the second post-migration period the earnings-related pension benefits increase with the size of immigrant population if

$$
\varepsilon<\frac{(1+\mu)^{\frac{1-\alpha}{\alpha^{2}}}-1}{\mu},
$$

and decrease otherwise.

Proof. Based on (12) and (27):

$$
p_{2}^{e r}=\tau^{e r} n \hat{w} \frac{1+\mu}{\left((1+\mu \varepsilon)^{\alpha}(1+\mu)\right)^{\alpha}} .
$$

As before the pre-migration steady state value of the earnings-related pension benefits is $\hat{p}^{e r}=\tau^{e r} n \hat{w}$, which is less than $p_{2}^{e r}$ if the above condition is satisfied, while otherwise $\hat{p}^{e r}>p_{2}^{e r}$.

Proposition 6 In the second post-migration period the demogrant pension benefits 
increase with the size of immigrant population if

$$
\varepsilon>\frac{(1+\mu)^{\frac{\alpha}{1-\alpha^{2}}}-1}{\mu}
$$

and decrease otherwise.

Proof. Based on (14) and (27):

$$
p_{2}^{d}=\tau^{d} n \hat{w} \frac{1+\mu \varepsilon}{\left((1+\mu \varepsilon)^{\alpha}(1+\mu)\right)^{\alpha}} .
$$

As before the pre-migration steady state value of the earnings-related pension benefits is $\hat{p}^{d}=\tau^{d} n \hat{w}$, which is less than $p_{2}^{d}$ if the above condition is satisfied, while otherwise $\hat{p}^{d}>p_{2}^{d}$.

As proposition (5) shows, immigration increases the level of earnings-related pension benefit, i.e. $p_{2}^{e r}>\hat{p}^{e r}$, under rather permissive condition. However, in order for the second post-migration period demogrant pension benefits to be higher than the pre-migration level, rather restrictive constraint needs to be satisfied. That is, because of the redistributive nature of demogrant pension system immigration of low-skilled migrants decreases the pension benefits. Similar to the corollary to the propositions 1 and 2, it can be concluded that the effect of the immigration on the pension benefits depends on the size and the skill level of the immigrant population as well as on the BF. A conjecture (similar to the one in the section above) can be made to claim that in the case of a high BF the initial young population will benefit from low skilled immigration; and in the case of a low BF environment they will benefit from the same if the pension benefit losses are not excessively large.

Hence in political equilibrium, with public voting, the initial population (both young and retired) will vote for the positive migration of low-efficiency immigrants 
though in the long-term that policy is welfare impairing for future generations. ${ }^{4}$

\subsection{Numerical Example}

This section uses examples of the United Kingdom and Germany to discuss results and conjectures of the previous sections. The two countries have been chosen as the two extremes: While the United Kingdom has implemented tight immigration policy (despite EU directives) and has exercised a fully distributive pension system (low BF), Germany has been more liberal in immigration policy (supporting EU free labour movement and Aussiedler return policies) and has exercised more actuarially fair pension system (high BF).

For both countries there is a working assumption that $\alpha=.4$, and immigration $\mu=5$ per cent. The tax rates are chosen so that they match the Bismarckian factors provided in Krieger \& Traub (2013) and the pension replacement rates from (Table 7 of) Eichhorst et al. (2011), i.e. $\tau^{e r}=11.2$ and $\tau^{d}=9$ per cent for Germany and $\tau^{e r}=1$ and $\tau^{d}=18$ per cent for the UK. Both countries reach their new steady states before the 13th cohort is born.

Figure 1 illustrates the above-described dynamics for welfare (the left-hand side) and pensions (the right-hand side) in the United Kingdom (above) and Germany (below). The horizontal axes show the immigrant efficiency level (compared to the natives) and the agents born during the respective period (with the initial retired population being the first cohort). In each graph, the pre-migration equilibrium levels are presented for comparison.

\section{[Insert figure 1 here]}

The results of the proposition 4, i.e. pure gains in pension benefits for initial retired people, are clearly visible for both countries (the right-hand side of the rows).

\footnotetext{
${ }^{4}$ The result is surely bounded by many modelling assumptions, such as the absence of altruism towards future population, or the absence of the possibility for the future population to reverse the results (such as the repetitive voting considered in Razin et al. (2011)).
} 
Comparison of the two graphs will illustrate the results of the propositions 1,2 , 5, 6 and their respective corollaries. As the UK pension system is characterised with a very small $\mathrm{BF}$, the post-migration steady state level of pension benefits decrease with migration once the efficiency of the immigrant population, $\varepsilon$, is less than 65 per cent of the efficiency level of the native population. While in Germany the total pension benefits increase once the efficiency level of the immigrant population is more than 23 per cent. Moreover, given the high BF in Germany the result of the proposition 5 prevails over the result of the proposition 6 and the total pension benefits for the initial young increases for any skill (efficiency) level of the immigrant population.

Further, figure 1 shows that the conjectures made on the general welfare hold for both cases, i.e. post-migration welfare decreases with migration as a result of capital dilution and even the gains in pension benefits from skilled migration is offset by the losses in wages. However, in line with the theoretical results, initial retired population only gain from migration and the gains increase with the increase in the skill level of the immigrant population. As for the initial young population, their general welfare gains are the highest in the case when immigrant population has the lowest efficiency and the welfare decreases with the increase in the efficiency levels. Again, the comparison of the UK and German cases shows the role of the BF: The threshold for the initial young population in the UK to gain from immigration is 59 per cent, while in Germany the initial young gain when the skill level of the immigrant population is as high as 68 per cent of the skill level of the native population.

The figure also presents actual results of the UK and German migration policies. Thus, table 1 in Algan, Dustmann, Glitz and Manning (2010) claims that the native hourly wage in the UK is 11.12 , while immigrants earn on average 11.48, 
which combined with the data of a 73.1 per cent of immigrant labour force participation rate as opposed to a native 79 per cent, gives $\varepsilon=.955$. Meanwhile, the same table shows that the lowest skilled immigrant group has an hourly wage of 6.26 , and only 55.7 per cent of them are employed, which produces $\varepsilon=.399$. The actual German immigrants (based on similar calculations) have an efficiency level of 85 per cent of the native born, while the lowest group has just 40 per cent.

Thus, in the environment of the current model the public choice (voting) model interpretation of the actual data suggests gerontocracy in the UK and Germany, i.e. the preferences of the initial old define the immigration policy (and cause welfare losses for current young population as well as for future generations). The social planner model would also predict very large weights on current old generation (again can be interpreted that in a gerontocratic environment the planner may be biased). However, the data fit a social planner model, which uses the effect of migration on the public finances as a guide for policy-setting (such as in Razin et al., 2011): In highly distributive UK economy (high BF) the pointsystem is implemented to guarantee gains, and in more actuarially fair German environment immigration policy is less strict on the skill level of the immigrant population. (This reasoning can also be used in explaining the UK restriction on immigrants from new and poorest EU member states.) Alternatively the data can be interpreted in lines with the recent findings in political science: Thus according to Hainmueller and Hiscox (2010) voter attitudes toward immigration is not explained by economic, but rather by 'ethnocentric or sociotropic' considerations.

\section{Conclusion}

The challenge from growing ageing population on unfunded public pensions has long been studied in economics. Possible measures are fewer pension benefits, 
larger contributions (including late retirement), fertility enhancement programmes, and replacement immigration. A vast literature now exists dealing with the last.

At the height of the discussion, Razin and Sadka (1999) introduced the idea of unskilled immigration solving the pension problem in an infinitely living economy (even with purely redistributive, demogrant, Beveridgean pension policy). The idea is simple: Unskilled immigrant workers enter the economy and, together with the native-born, working-age population, contribute to the old-age pension system. When those immigrants age, natives have to share their pensions with them; however, larger cohorts of the native-born (including the children of immigrants) would contribute to the pensions of old-age immigrants. Effectively, the economy borrows from the very last generation (absurd in an infinitely living economy) and elevates the welfare of all involved parties.

Many (including the mentioned authors themselves) rebelled at the idea of pure benefit of unskilled immigration and proposed various mechanisms that challenge the general welfare of the involved parties. Prices, unemployment, child costs and the like have been proposed as possible sources for general welfare deprivation. However, the current work counter-argues the very idea of unskilled immigrants serving to sustain the pension system. It is shown that while the unskilled immigration increases pension benefits compared to wages, it decreases capital available per each worker and, thus, also wages. As a result the demogrant pension benefits (the one used in Razin and Sadka, 1999) decrease.

However, the earnings-related (actuarially fair, Bismarckian) pensions, which are widely found in many countries combined with demogrant pensions, are shown to generate higher pension benefits compared to pre-immigration levels. Thus the effect of low-skilled migration on overall pension levels depends on the share of earnings-related pension benefits (the Bismarckian factor) and the level of immi- 
grant labour efficiency.

Further it is shown that the overall welfare of all agents (with the exception of the initial population) decreases with unskilled immigrants. Meanwhile, the initial retired population benefit from immigration (still preferring better skilled migrants) due to direct pension benefit increases, and the initial young population prefer migrants with low skill only in order to boost the interest on their savings while faced with little loss in wage rates. As a result, should a policy be set based on the preferences of the current population (i.e. if public choice prevails), an unskilled immigration policy would be established resulting in reduced pension benefits (and welfare) for future population. The real data interpretation of the model suggests that either political gerontocracy prevails in the discussed European states or the immigration policy is set on the basis of public finances only. 


\section{References}

[1] Algan Y, Dustmann C, Glitz A, Manning A (2010) The economic sitation of first and second-generation immigrants in France, Germany and the United Kingdom. Econ J 120: F4-F30

[2] Blake D, Mayhew L (2006) On the sustainability of the UK state pension system in the light of population ageing and declining fertility. Econ J 116: F286-F305

[3] Casarico A, Devillanova C (2003) Social security and migration with endogenous skill upgrading. J Public Econ 87: 773-797

[4] Chojnicki X, Docquier F, Ragot L (2011) Should the US have locked heaven's door? Reassessing the benefits of postwar immigration. J Popul E 24: 317-359

[5] Cigno A (2010) How to avoid a pension crisis: A question of intelligent system design. CESifo Econ Stud 56: 21-37

[6] Cigno A (2006) A constitutional theory of the family. J Popul Econ 19: 259283

[7] Cipriani GP (2013) Population aging and PAYG pensions in the OLG model. J Popul Econ. doi:10.1007/s00148-013-0465-9

[8] Cremer H, Gahvari F, Pestieau P (2011) Fertility, human capital accumulation, and the pension system. J Pub Econ 95: 1272-1279

[9] Cremer H, Pestieau P (1998) Social Insurance, majority voting and labor mobility. J Pub Econ 68: 397-420 
[10] Eichhorst W, Gerard M, Kendzia MJ, Mayrhuber C, Ruestler G, Url T (2011) Pension systems in the EU - Contingent liabilities and assets in the public and private Sector. IZA Research Rept No42

[11] Fanti L, Gori L (2013) Fertility-related pensions and cyclical instability. J Popul E 26: 1209-1232

[12] Fanti L, Gori L (2012) Fertility and PAYG pensions in the overlapping generations model. J Popul Econ 25: 955-961

[13] Fanti L, Gori L (2010) Increasing PAYG pension benefits and reducing contribution rates. Econ Lett 107: 81-84

[14] Hainmueller J, Hiscox MJ (2010) Attitudes toward highly skilled and lowskilled immigration: Evidence from a survey experiment. Am Polit Sci Rev 104: $61-84$

[15] Jinno M (2011) Assimilation, immigration, and the welfare state. FinanzArchiv 67: 46-63

[16] Kemnitz A (2008) Can immigrant employment alleviate the demographic burden? The role of union centralization. Econ Lett 99: 123-126

[17] Kemnitz A (2003) Immigration, unemployment and pensions. Scand J Econ 105: $31-47$

[18] Krieger T, Traub S (2013) The Bismarckian factor: A measure of intragenerational redistribution in international pension systems. CESifo DICE Report $1 / 2013$

[19] Krieger T (2004) Fertility rates and skill distribution in Razin and Sadka's migration-pension model: A note. J Popul Econ 17: 177-182 
[20] Lacomba JA, Lagos F (2010) Immigration and pension benefits in the host country. Econ 77: 283-295

[21] Lee R, Miller T (2000) Immigration, social security, and broader fiscal impacts. Am Econ Rev 90: 350-354

[22] Muysken J, Cörvers F, Ziesemer T (2011) Immigration can alleviate the ageing problem. Netspar Discuss Pap DP07/2011-058

[23] Okkerse L (2008) How to measure labour market effects of immigration: A review. J Econ Surv 22: 1-30

[24] Razin A, Sadka E (2000) Unskilled migration: A burden or a boon for the welfare state? Scand J Econ 102: 463-479

[25] Razin A, Sadka E (1999) Migration and pension with international capital mobility. J Public Econ 74: 141-150

[26] Razin A, Sadka E, Suwankiri B (2011) Migration and the Welfare State. Cambridge, MA: MIT Press

[27] Schou P (2006) Immigration, integration and fiscal sustainability. J Popul Econ 19: 671-689

[28] Serrano F, Eguía B, Ferreiro J (2011) Public pensions' sustainability and population ageing: Is immigration the solution? Int Labour Rev, 150: 63-79

[29] Song Z, Storesletten K, Zilibotti F (2007) Rotten parents and disciplined children: A politico-economic theory of public expenditure and debt. Econom 80: $2785-2803$

[30] Storesletten K (2000) Sustaining fiscal policy through immigration. J Polit Econ 108: 300-323 
[31] Übelmesser S (2004) Unfunded Pension System: Ageing and Migration. Amsterdam, NL: Elsevier 

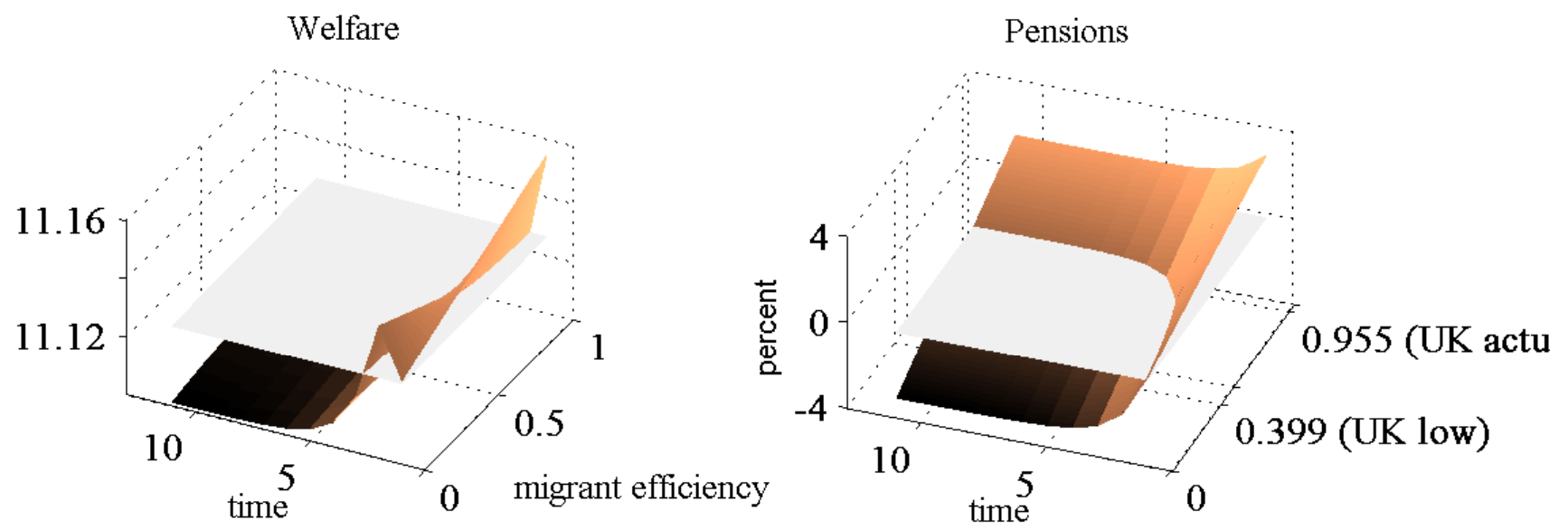

a) United Kingdom
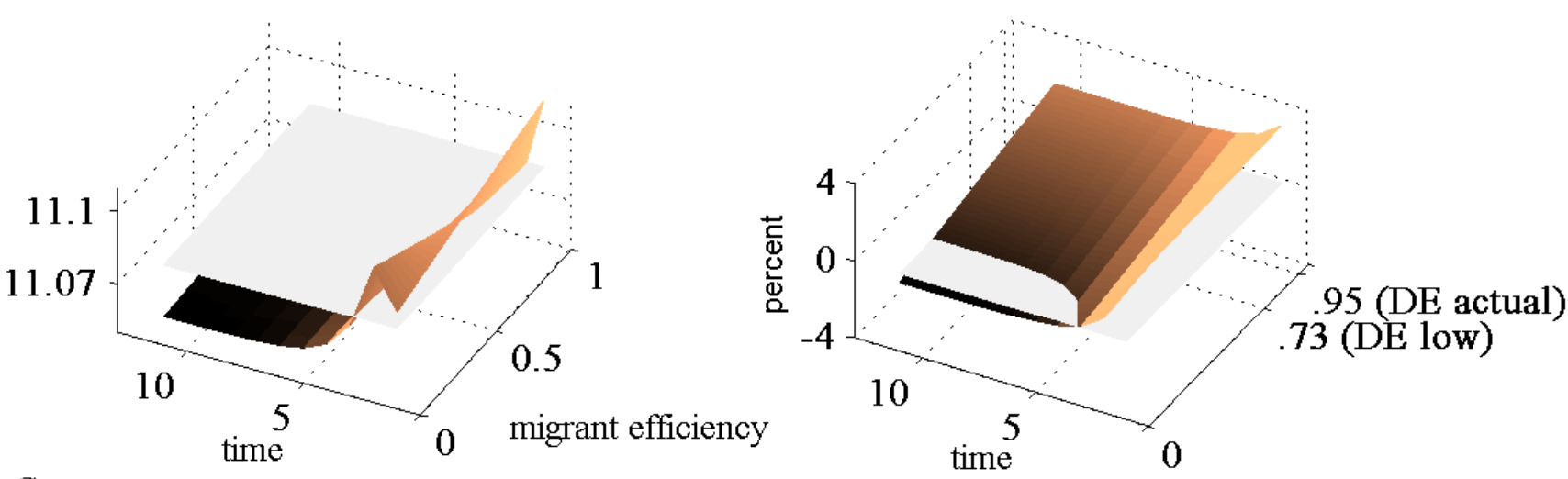

b) Germany

Figure 1: Transition dynamics for pension benefits (right-hand side) and the general welfare (left-hand side) for the UK (top row) and Germany (bottom row) 